\title{
Projeto Borboletas: a apropriação das tecnologias na aprendizagem por projetos
}

\section{Project butterflies: the appropriation of technology in learning by projects}

\begin{abstract}
Resumo: A apropriação das tecnologias no processo ensino-aprendizagem dos alunos consiste numa alternativa viável. O presente texto é o relato de um projeto realizado com uma turma de $1^{\circ}$ ano do ensino fundamental, em uma escola pública de educação básica. O objetivo deste artigo é apresentar um relato de experiência acerca de como o uso das tecnologias podem contribuir com a aquisição de habilidades e competências que são a base para que a criança se desenvolva. Os resultados revelaram que o engajamento dos alunos nas atividades foi bastante satisfatório e que seu uso pode ser aplicado no contexto escolar e se mostram aliados na construção da aprendizagem.

Palavras-chave: Tecnologia. Processo ensino-aprendizagem. Contexto escolar.
\end{abstract}

\begin{abstract}
The appropriation of technology in the teachinglearning process of the students is a viable alternative. This paper is a report on a project conducted with a group of 1 st year of elementary education in a public school of basic education. The objective of this paper is to present an experience report on how the use of technology can contribute to the acquisition of skills and competencies that are the foundation for the child to develop. The results revealed that student engagement in activities was quite satisfactory and that its use can be applied in the school context and show themselves allies in the construction of learning.

Keywords: Technology. Teaching-learning process. School context.
\end{abstract}

OLIVEIRA, Aletheia Machado de. Projeto Borboletas: a apropriação das tecnologias na aprendizagem por projetos. Informática na Educação: teoria e prática, Porto Alegre, v. 18 , n. 1 , p. 19-25, jan./jun. 2015.

\author{
Aletheia Machado de Oliveira \\ Pontifícia Universidade Católica de Minas Gerais
}

\section{Introdução}

A realização de projetos no cotidiano escolar representa um procedimento eficaz no cenário educacional, pois estabelece uma estreita relação entre a aprendizagem que acontece dentro da escola e a experiência da criança.

A aprendizagem por projetos incentiva as crianças a investigar e explorar assuntos que sejam interessantes e motivadores para ela, favorecendo a produção de novos conhecimentos dentro de um contexto realmente significativo, uma vez que participam efetivamente da construção do conhecimento através de atividades dinâmicas como pesquisa e troca de ideias, que as levam a refletir continuamente, durante o processo, sobre a importância do que está sendo estudado. Também vale ressal- 
tar que esta criança ao interagir com o grupo e com os professores, desenvolve valores como respeito e solidariedade.

Nas palavras de Petitto (2003), os projetos de trabalho permitem a análise de problemas, situações e acontecimentos de um contexto, bem como a oportunidade de reflexão e a construção da aprendizagem. Não devem ser pensados como método, mas sim uma prática educativa. O enfoque principal está no aprender a aprender, em que o aluno utiliza todo tipo de informação para seu aprimoramento pessoal. O aluno transforma informação em conhecimento, com aplicação à realidade.

Nesta perspectiva, a apropriação das tecnologias poderá potencializar este processo. Para tanto, requer projetos educacionais bem definidos e articulados com o projeto político pedagógico da escola e discussões constantes entre professores/gestores/alunos quando estamos relacionando tecnologia/processo ensino-aprendizagem. É uma ótima ferramenta mediadora de promoção da aprendizagem, pois incentiva a criatividade, a pesquisa, transforma informação em conhecimento, tornando o aprendizado mais dinâmico e motivador.

Neste sentido, o texto está organizado como segue. Na seção 2 é feita uma reflexão sobre o papel das tecnologias no contexto educacional. A descrição da experiência está relatada na seção 3. Os resultados são apresentados na seção 4. As considerações finais são descritas na seção 5 .

\section{Fundamentação Teórica}

No mundo contemporâneo vivenciamos um tempo de transformações tecnológicas denominada por Castells (1999) como a revolução da tecnologia da informação e que veio a pro- duzir alterações significativas nas diversas esferas sociais. A sociedade passa a ganhar uma nova configuração que se reflete em novas formas de viver, de trabalhar, nas relações interpessoais, na cultura e na educação.

Nesse processo de mudanças, o processo ensino-aprendizagem apresenta-se em constante transformação com a inserção das tecnologias (especificamente o computador) no cotidiano escolar. Dalben e Castro (2010) afirmam que

[...] os impactos provocados pelas tecnologias contemporâneas de comunicação e informação, traduzidas na facilidade de acessar, selecionar e processar informações refletem na educação, permitindo alargar as novas fronteiras do conhecimento por meio de uma relação pedagógica permanente de diálogo e de interação entre os saberes (DALBEN; CASTRO, 2010, p. 39).

Isso denota, portanto, que a relação tecnologia/educação não poder ser pensada de forma dissociada, mas articulada ao processo educativo. A tecnologia está presente na sociedade e na educação e não pode ser ignorada. Logo, essa relação deve ser pautada por uma atitude reflexiva, construtiva, ativa no contexto escolar.

O papel da educação é o de criar condições para que o processo ensino-aprendizagem seja significativo para os alunos, uma vez que a revolução tecnológica oferece uma nova forma de adquirir conhecimento e de formação para enfrentar as exigências do mundo contemporâneo. Com isso, adquire-se novo dinamismo com a penetrabilidade da tecnologia no processo educativo e grandes reestruturações nos conteúdos, currículos, espaços escolares e na capacitação dos docentes, objetivando superar um ensino tradicional baseado na simples função de transmitir conteúdos, para um ensino 
mais interativo, cooperativo, instigador e reflexivo (DALBEN; CASTRO, 2010).

Nesse novo cenário, a utilização das tecnologias no contexto educacional tem ganhado cada vez mais espaço no ambiente escolar. Observa-se que muitas escolas apresentam diferentes estratégias de inserção das tecnologias na construção desse ambiente de aprendizagem $^{1}$.

Marinho (2013) em seu artigo O Cenário do Uso das Tecnologias na Escola do Século $X X I$ nos diz que dar um sentido à tecnologia no contexto escolar significa compreendê-la como ferramenta física, simbólica, social, a serviço do saber e de um saber-fazer que propiciará a construção de conhecimentos e de novas aprendizagens.

Para tanto, temos na literatura as teorias do conhecimento que foram sendo construídas na tentativa de compreender a dinâmica do ato de ensinar e aprender e ajudar no trabalho com as tecnologias da informação e comunicação. Nas palavras de Dalben e Castro (2010), essas concepções revelam diferentes formas de explicar as dimensões biológicas e culturais do homem e a forma pela qual eles aprendem e se desenvolvem, sendo cada uma marcada por um contexto sócio-histórico.

[...] as concepções sobre o papel e as abordagens da relação pedagógica construída no corpo de propostas educativas são diferentes em contextos históricos diversos e estão sempre em conflito. Essas concepções apontam para a criação de novas alternativas de ensino que implicam mudanças nos currículos, métodos, estratégias de ensino, formas de relacionamento com a escola, com os do-

\footnotetext{
1 Segundo Oliveira, Costa e Moreira (2004), os ambientes de aprendizagem são espaços do saber favorecedores da construção do conhecimento e a escola permite a efervescência desses ambientes. Eles criam oportunidade de integração entre várias matérias, propiciam ao aluno atitude exploratória e autonomia e o professor é o mediador.
}

centes e discentes, na perspectiva de atendimento a todos os alunos em sua diversidade cultural, social e ética (DALBEN; CASTRO, 2010, p.13).

Nesse contexto, em que são baseadas nas escolas psicológicas, elas podem apresentar três características: primado do objeto, primado do sujeito e interação entre sujeito-objeto cujo processo no ambiente educacional não deve ser observado apenas em sua totalidade, mas englobando aspectos referentes ao ensino, conhecimento, relação professor/aluno, homem/mundo, cultura, educação, entre outros. (MIZUKAMI, 1986).

Do ponto de vista do interacionismo, característica que fundamentou nosso trabalho, advoga-se a existência de uma relação recíproca entre desenvolvimento e aprendizagem onde essa relação ocorre durante toda a vida entre o indivíduo e o meio e destes sobre ele. Não há uma essência humana, mas uma construção do indivíduo em constante atividade de adaptação a um ambiente. Em relação ao aspecto pedagógico, professor e aluno participam conjuntamente do processo educativo numa relação dialógica e cooperativa. O conhecimento é dinâmico e está em transformação contínua. O objetivo é conduzir o aluno à reflexão crítica sobre sua participação na sociedade e sobre sua própria capacidade de transformá-la. (DALBEN; CASTRO, 2010, MIZUKAMI, 1986).

\section{Descrição da Experiência}

\subsection{Planejamento}

Este projeto contou com a participação de duas professoras que atuavam em sala de aula. O planejamento deste projeto foi dividido em duas etapas. A primeira etapa consistiu na 
apresentação do projeto à direção da escola e aos pais dos alunos envolvidos. Na segunda etapa, após o consentimento de ambas as partes, foram realizadas uma pesquisa em conjunto com as professoras para a elaboração e seleção de estratégias de ensino a fim de articular as tecnologias (em especial o computador) a partir do interesse demonstrado pelos alunos sobre a vida das borboletas.

\subsection{Caracterização dos Participantes}

O projeto foi desenvolvido em uma turma composta de vinte e quatro alunos, sendo dezenove do sexo feminino e cinco do sexo masculino. A faixa etária era de 06/07 anos de idade. Todos já possuíam domínio no computador, uma vez que eles tinham a oportunidade de vivenciar no laboratório de informática da própria escola e alguns tinham acesso em casa. Com o propósito de preservar a identidade dos alunos, passam a ser referidos pela abreviatura formada pela letra $A$ seguida de número.

\subsection{Ações Desenvolvidas}

O processo de escolha do projeto aconteceu em sala durante uma atividade de linguagem oral, a partir da apresentação do poema As Borboletas de Vinícius de Moraes, momento em que alguns alunos questionaram sobre a vida das borboletas. Diante da situação, percebemos que os conhecimentos iniciais, as certezas provisórias, que apresentaram sobre o tema referiam-se às vivências diárias e contatos diretos com o animal em seus lares e em outros locais que eles tinham acesso (na rua, na escola...).

Durante a conversa informal com esses alunos, selecionamos alguns questionamentos fei- tos sobre a borboleta: De onde elas nascem? (A5), Como elas se transformam em borboletas? (A7), Como as borboletas têm filhotes? (A3), A borboleta tem casa? (A12), A borboleta tem osso? (A9), O que a borboleta come? (A15), Quanto tempo a borboleta vive? (A1).

Muitos relataram, também, que já haviam visto uma borboleta e um casulo: Eu vi uma borboleta amarela voando no quintal da minha casa (A6), A borboleta gosta de flor (A13), No quintal da minha casa, tem um casulo (A18).

Partindo, então, desses questionamentos e de conhecimentos prévios foi proposto à turma que estudássemos sobre o animal integrando as tecnologias ao contexto. As estratégias utilizadas para atingir os objetivos e metas estabelecidos no projeto foram: as conversas informais na rodinha, apresentação de imagens e vídeos sobre o nascimento da borboleta, produção de texto coletivo, desenhos no Paint e HagáQuê e utilização de jogos educativos. O trabalho foi organizado em seis momentos e com duração de um mês. Ao final de cada momento, foi realizado o registro do que estava sendo proposto.

No primeiro momento foi feita uma rodinha na sala de aula com todos os alunos para responder às dúvidas levantadas por eles, conforme os questionamentos levantados pelas crianças. Utilizamos de imagens capturadas da Internet para responder às dúvidas e o livro $A$ Reprodução das Borboletas da autora Suzana Facchini Granato e ilustradora Neide Simões de Mattos.

No segundo momento, os alunos foram divididos em grupos de seis para irem ao laboratório de informática e registrarem em forma de desenhos, no Paint, o que foi discutido no primeiro momento. O software Paint é um programa que dispõe de uma variedade enorme de recursos, em que a criança consegue es- 
colher qual ferramenta usará, não sendo conduzida a realizar uma atividade pré-definida. Com a intenção de ilustrar uma dessas atividades, a Figura 1 representa essa ação:

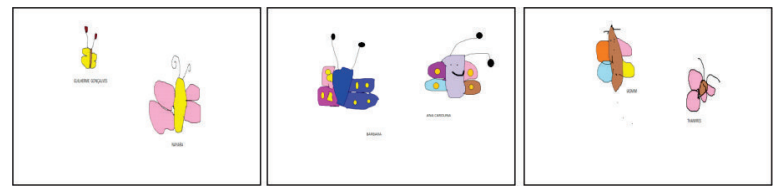

FIGURA 1 - Desenho no Paint FONTE: Elaborado pela autora.

No terceiro momento, os alunos foram à biblioteca da escola para assistirem aos vídeos selecionados sobre o tema. Como recurso, usamos o DataShow para assistir aos vídeos. Em seguida, quarto momento, foi realizado em sala o registro dos vídeos através de uma produção de texto coletiva. A Figura 2 nos mostra esse momento:
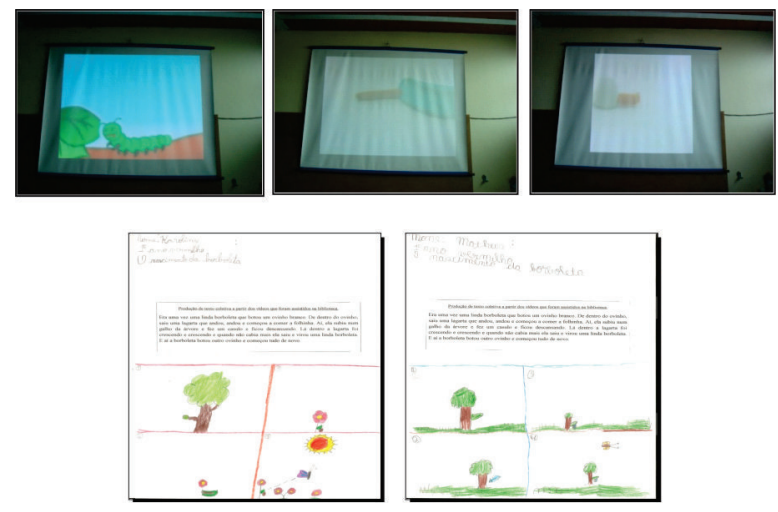

FIGURA 2 - Uso do DataShow e Produção de Texto Coletiva FONTE: Elaborado pela autora.

No quinto momento os grupos ficaram responsáveis por registrar, em forma de desenhos, cada fase da borboleta no Paint. Ao final foi construída uma História em Quadrinhos com a sequência de crescimento da borboleta.
Utilizamos o software HagáQuê por apresentar alguns aspectos positivos, a saber: possibilidade de impressão e de publicização; ampliação das atividades de leitura e escrita para além do ambiente digital e estímulos motivadores: autoria, interatividade, autoestima, criatividade e autonomia.
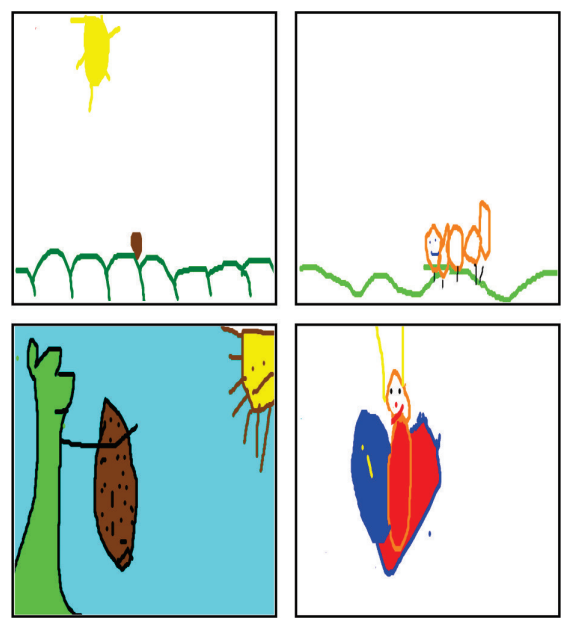

FIGURA 3 - Uso do Software HagáQuê FONTE: Elaborado pela autora.

$\mathrm{E}$, no último momento, dividimos a turma em dois grupos para irem ao laboratório de informática e utilizar os jogos educativos pesquisados e testados por nós previamente. Os jogos educativos devem ser aplicados com cautela e direcionamento e devem vir ancorados no bom planejamento, com objetivos claros e metodologia articulada. No caso de sua aplicação, neste projeto, percebemos que sua utilização ajudou a desenvolver aspectos, tais como: percepção, atenção/concentração, discriminação visual e auditiva, coordenação motora fina e grossa, tomada de decisões, correspondência de ideias, entre outros. 


\section{Avaliação dos Resultados}

A avaliação do projeto aconteceu através de uma auto avaliação, como ilustra a Figura 4. Como esses alunos ainda estavam em processo de alfabetização, utilizamos como estratégia o uso de carinhas que significavam gostei, gostei mais ou menos e não gostei para o registro de sua preferência. Todos os vinte e quatro alunos responderam de forma positiva às atividades que foram propostas e aplicadas no decorrer do projeto.
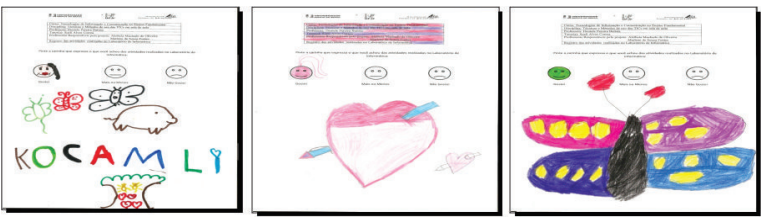

FIGURA 4 - Auto Avaliação dos Alunos FONTE: Elaborado pela autora.

Observamos que houve um grande envolvimento e comprometimento dos grupos na realização das atividades propostas. Percebemos que, quando envolvidos em atividades significativas, seu interesse para o aprendizado aumenta. Constatou-se que a organização dos aprendizes em grupos promove uma maior interação e ajuda mútua entre eles, contribuindo para uma melhor aprendizagem. A utilização dos recursos tecnológicos pelos alunos aconteceu de forma tranquila apresentando bom desempenho na concretização das atividades e evidenciou o quanto é importante articulá-la ao planejamento pedagógico, uma vez que possibilitou aos aprendizes a aquisição de habilidades (psicomotoras, sociais, cognitivas) e competências para a efetividade da aprendizagem.

\section{Considerações Finais}

Por meio dessa experiência, consideramos que os alunos apresentaram grande interesse e entusiasmo em realizar as atividades propostas, questionaram, manifestaram preferências, demonstraram alguns avanços referentes ao manuseio do mouse, compreensão do conteúdo em estudo, leitura e escrita. Consideramos como relevante a curiosidade, o entusiasmo e o avanço que os alunos demonstraram durante todo o projeto, como consequência do interesse do conteúdo e do uso das ferramentas tecnológicas em várias atividades.

Percebemos que, as crianças que tem contato com a tecnologia, ficam expostas a uma gama enorme de estímulos. Não é preciso aprender apenas em meios tradicionais, mas com a apropriação consciente das tecnologias no contexto de sala de aula. É possível, sim, integrar tecnologia e educação.

Não existem conclusões que deem conta de finalizar este trabalho, porém, existem algumas considerações acerca da experiência que vivenciamos e podemos destacar:

a) é papel da escola permitir que a criança interaja com os mais diversos recursos pedagógicos e devem fazer parte da rotina diária o uso da tecnologia, em especial o computador;

b) as tecnologias podem ser aplicadas ao contexto da educação e, se mostram como aliados na construção de habilidade e competências. É, portanto, imprescindível que essa máquina seja direcionada como uma ferramenta mediadora do processo ensino-aprendizagem;

c) para que o trabalho tenha êxito, é fundamental que todos os atores do processo 
educativo estejam engajados e com um bom planejamento para o uso consciente dessas tecnologias.

\section{Referências}

CASTELLS, M. A Revolução da Tecnologia da Informação. In: CASTELLS, Manuel. A Sociedade em Rede: a era da informação: economia, sociedade e cultura. 8. ed. São Paulo: Paz e Terra, 1999. Cap. 1 , p. 67-118.

CHAVES, E. Sua Escola a 2000 por Hora: educação para o desenvolvimento humano pela tecnologia digital. São Paulo: Instituto Ayrton Senna; Saraiva, 2004.

DALBEN, A.I.L.F.; CASTRO, E.V. A Relação Pedagógica no Processo Escolar: sentidos e significados. In: TEIXEIRA, A.B.M. Temas Atuais em Didática. Belo Horizonte: Ed. UFMG, 2010. Cap. 1, p. 13-61.

GRANATO, S.F. A Reprodução das Borboletas. Ilustração de Neide S. de Mattos. São Paulo: Ed. SM, 2008.

MARINHO, V.C. O Cenário do Uso das Tecnologias na Escola do Século XXI. In: WORKSHOP DE INFORMÁTICA NA ESCOLA, 19., 2013, Campinas, SP. Anais... Campinas, SP: Unicamp, 2013. Disponível em: <http://www.br-ie.org/pub/index.php/wie/article/view/2605> Acesso em: 12 jun. 2014.

MIZUKAMI, M.G.N. Ensino: as abordagens do processo. 5. ed. São Paulo: EPU, 1986.

OLIVEIRA, C.C.; COSTA, J.W.; MOREIRA, M. Ambientes Informatizados de Aprendizagem. In: COSTA, J.W.; OLIVEIRA, M.A.M. (Org.). Novas Linguagens e Novas Tecnologias: educação e sociabilidade. Petrópolis, RJ: Vozes, 2004. Cap. 4, p. 111-138.

PETITTO, S. Projetos de Trabalho em Informática: desenvolvendo competências. Campinas, SP: Papirus, 2003.

Submetido para avaliação em 03 de maio de 2014.

Aprovado para publicação em 09 de abril de 2015.

Aletheia Machado de Oliveira - Pontifícia Universidade Católica de Minas Gerais, Belo Horizonte, BR-MG. E-mail: aletheiaoliveira@yahoo.com.br 